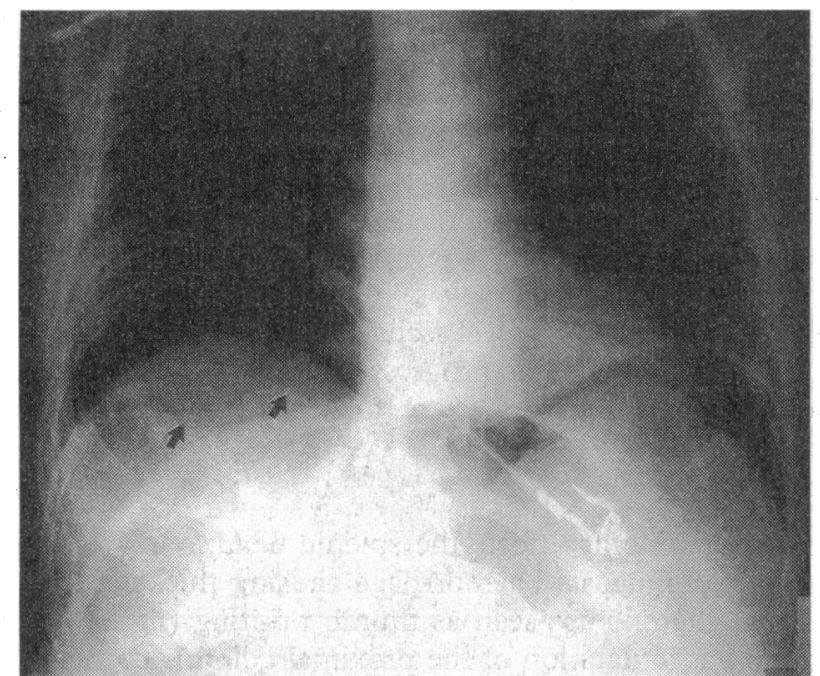

FIG 10-Erect chest radiograph showing a large pneumoperitoneum with air under both diaphragms. The right hemidiaphragm is raised. Dilated air filled loops of bowel are projected over the liver (arrows) - both sides of the bowel wall can be seen (Rigler's sign).

Summary
Diagnostic quality
Alignment of bones
Bone margins and density
Cartilage and joints
Soft tissues
Bowel gas pattern
Pneumoperitoneum
Air in the biliary tree or portal vein
Size of organs
Fat-tissue interfaces
Abnormal calcification

D A Nicholson is consultant radiologist and P A Driscoll is senior lecturer in emergency medicine, Hope Hospital, Salford.

The ABC of Emergency Radiology has been edited by David Nicholson and Peter Driscoll.

\title{
Minimally Invasive Surgery
}

\section{Treatment of urinary tract stones}

\section{JE A Wickham}

This is the third in a series of articles describing current techniques in minimal access surgery. The articles have been written to inform non-specialists of developments in this rapidly moving subject.
Division of Minimally Invasive Surgery, Combined Medical and Dental Schools of Guy's and St Thomas' Hospital, London

J E A Wickham, senior research fellow

BMF 1993;307:1414-7
Replacement of open surgery with minimally invasive techniques for treating stones in the renal tract has greatly reduced patients' morbidity and mortality and the period of hospitalisation and convalescence. Extracorporeal shockwave lithotripsy does not require anaesthesia and requires little analgesia so that treatment can be given on an outpatient basis, and there is no wound to heal. Only a small puncture site is needed for percutaneous endoscopic lithotomy, and with the advent of prophylactic antibiotics there are few complications. Of renal stones, about $85 \%$ can now be successfully treated by extracorporeal lithotripsy alone, and almost all of the stones too large or hard for lithotripsy can be treated endoscopically, with ultrasonic or electrohydraulic probes being used to fragment the stone. Stones in the upper and lower thirds of the ureter can be treated by extracorporeal lithotripsy, but stones in the middle third, which cannot normally be visualised to allow focusing of the shockwaves, usually require ureteroscopy. Nearly all bladder stones can be treated by transurethral endoscopy with an electrohydraulic probe. Only the largest renal tract stones still require open surgery.

\section{The renal stone}

Ten years ago it was usual for a patient suffering from a painful renal stone to undergo an open operation with a $25 \mathrm{~cm}$ loin incision to access the kidney. Two hours of anaesthesia were followed by 10-14 days in hospital, during which the patient would suffer considerable pain and discomfort. The complications of a major surgical intervention-bronchopneumonia, pulmonary embolus, and wound infection-were not unusual. ${ }^{\prime}$ Six weeks' convalescence were necessary before normal activities could be resumed.
PERCUTANEOUS ENDOSCOPIC LITHOTOMY

In 1979 at the Institute of Urology, London, and at the University of Mainz, Germany, it was realised that just as a percutaneous nephrostomy tube could be inserted into the kidney under radiological control so it might be possible to pass an endoscope down a tube track to visualise a calculus and, if it was small, remove it. In Germany this approach was initially restricted to the removal of stones from tracks pre-established at open surgery, ${ }^{2}$ while in London the first truly elective endoscopic nephrolithotomies were performed and reported in $1981 .^{3}$ By 1983 several hundred patients had been treated in Europe and the United States. ${ }^{47}$ The operation dramatically lessened patients' morbidity and mortality but gave results as good as those obtained by open surgery. Hospitalisation lasted two to three days, and a return to full activity was possible within a week. Analgesic requirements and postoperative complications were much reduced. ${ }^{8-10}$ The technique was refined, and larger stones of all types were successfully treated with ultrasonic or electrohydraulic disintegratory probes passed down the endoscope.

Complications have largely been those of postoperative septicaemia, presumably from the introduction of infective material into open venous channels in the kidney. When this was recognised appropriate prophylactic antibiotics were introduced, and this has become much less of a problem. Patients with coagulopathies should not be treated by this technique since considerable haemorrhage can result as in open surgery. Venous bleeding may occur down the percutaneous tract, but this is easily tamponaded by inserting a nephrostomy tube. Very rarely, arterial bleeding from a segmental vessel may require selective embolisation. Open retrieval surgery is almost unheard of for control of bleeding. ${ }^{11}$ Few other complications have been experienced. 
EXTRACORPOREAL SHOCKWAVE LTTHOTRIPSY

In 1980 seven years' research and development in Munich, Germany, culminated in the first clinical application of extracorporeally induced focused shockwaves to fragment renal stones in humans. ${ }^{12}$ Other departments rapidly acquired lithotripters as it became apparent that this was an effective and atraumatic method of treating renal stones and that nearly all types of stone could be adequately fragmented. The electrohydraulically induced shockwaves; however, were painful so that the operation required a general anaesthetic, and some analgesia was needed for postoperative pain. Nevertheless, patients could return to work within a week with no wound to heal. Postoperative complications were negligible compared with open surgery.

The second generation lithotripters that appeared in 1985 were based on the induction of multiple minor shockwaves by an array of miniature piezoelectric cells. The shockwaves were transmitted through a water bath coupler to impinge at a $2 \mathrm{~mm}$ focus on a patient's stone, where their summation produced a local pressure of 150 kilobars and caused the stone to disintegrate. The major advantage of this machine was that it was painless; each shockwave travelling along an independent pathway through the body could not be appreciated by the patient. ${ }^{13}$ No anaesthesia was neces-

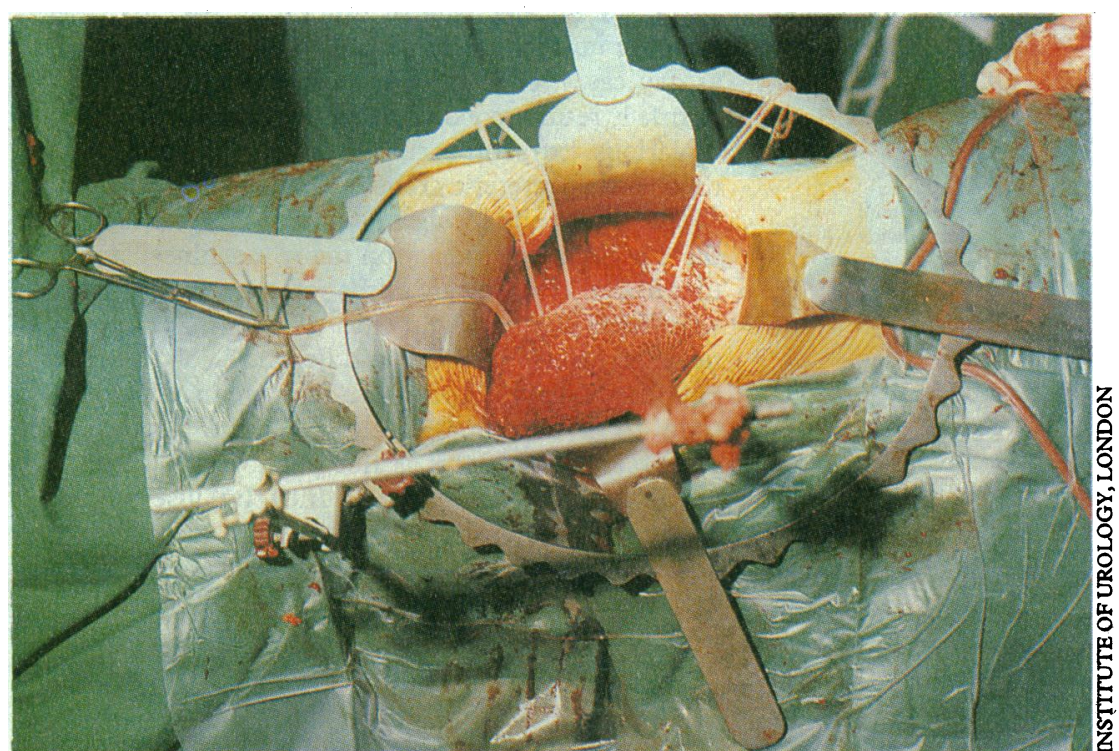

Access required for treatment of a urinary tract stone by open surgery. .

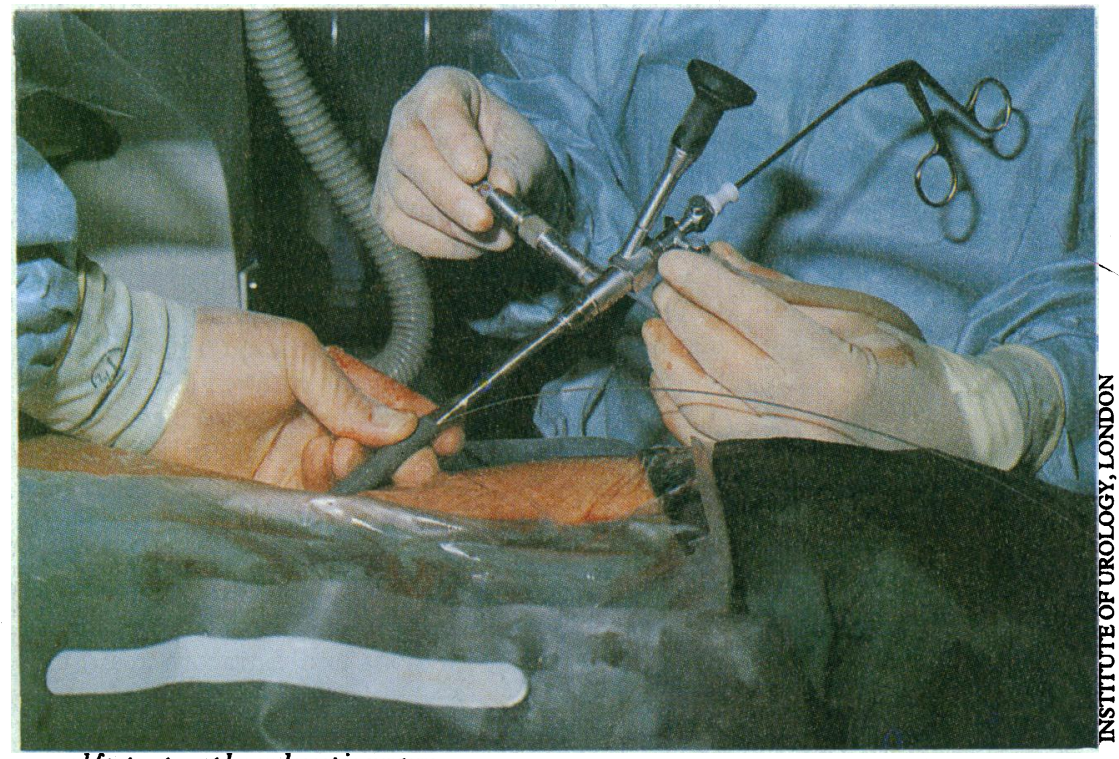

and for treatment by endoscopic surgery sary and analgesics were seldom required. The procedure could thus be performed on an outpatient basis and did not require hospitalisation. Postoperative complications were again negligible compared with open surgery, and nearly all types of stone could be treated satisfactorily. ${ }^{14} 15$

Electromagnetic machines, in which shockwaves were induced by intermittent repulsion of a metal membrane and focused by an acoustic lens, were also introduced. These machines were more painful, often requiring injection of local anaesthetic to the loin and strong analgesic cover, but were equally successful. Third generation machines with coaxial $x$ ray and ultrasound imaging appeared in the late 1980s. The type of lithotripter used seems relatively unimportant since all are effective, but more recent machines provide treatment on an outpatient basis with obvious economic advantage.

Complications seem minor. The possibility of the operation causing sustained hypertension has been reviewed ${ }^{1617}$ : the only study to demonstrate such an effect found that the small number of patients who developed raised blood pressure in the long term were no more than would be expected in a cohort of similar patients with slowly developing essential hypertension. ${ }^{18}$ This topic, however, merits further investigation. First generation, spark gap lithotripters have been shown to depress renal function and elevate renal enzyme activities for a few days after treatment, but all parameters measured rapidly return to normal. ${ }^{19-21}$ Piezoelectric lithotripsy has no measurable effect on renal function or enzymology. ${ }^{21}$ These reported changes should be kept in perspective-open surgery is very traumatic and produces far more morphological and functional renal damage. ${ }^{22}$ Another complication is ureteric obstruction by stone fragments passing down from the kidney. This occurs most often when a large renal stone is fragmented and can usually be averted by the preliminary insertion of a double $\mathrm{J}$ ureteric stent, which provides urinary drainage as well as dilating the ureter to encourage easier passage of stone particles. Should stone fragments become lodged in the ureter they can usually be treated by further targeted extracorporeal lithotripsy or mini-ureteroscopy with fragmentation by laser.

\section{CURRENT TREATMENT FOR RENAL STONE}

Results from most reported series, which are remarkably consistent, indicate that it is now possible to treat $85 \%$ of all simple renal calculi satisfactorily by extracorporeal lithotripsy alone. ${ }^{23}$ About $10-15 \%$ of stones are not suitable for lithotripsy because of their bulk or hardness, but they can almost always be managed by percutaneous endoscopic lithotomy. ${ }^{24}$ The $1 \%$ of stones that require open surgery are the massive staghorn calculi. Some of these difficult stones can be managed with a combination of endoscopic lithotomy and extracorporeal lithotripsy, ${ }^{2526}$ but this may require multiple procedures that are not economical in time or expense, and they are better managed with a single open procedure. As the size of stone increases patients are less likely to be completely free of stones after treatment with a minimally invasive technique since fragments can lodge elsewhere in the urinary tract. ${ }^{27}$

Certain stones provide specific problems in management-for example, very hard cystine stone ${ }^{28}$ and stones in calyceal diverticulae, ${ }^{29}$ horseshoe kidneys, ${ }^{30}{ }^{31}$ or medullary sponge kidneys, ${ }^{32}$ where drainage and evacuation of fragments may be difficult. Series have shown that these stones can be managed with a combination of extracorporeal shockwave lithotripsy and percutaneous nephrolithotomy. The treatment of renal stones in children is also possible by extracorporeal lithotripsy. ${ }^{334}$ 


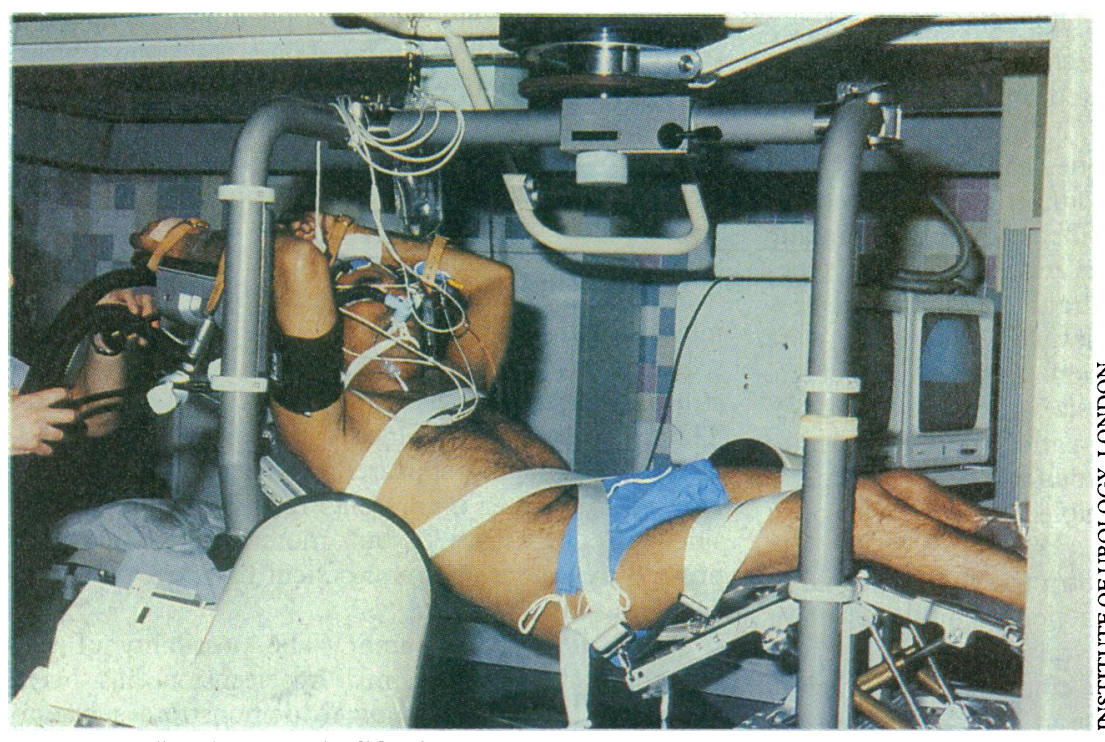

Patient in cradle of first generation lithotripter

Comparison of procedures for treatment of renal stroke

\begin{tabular}{|c|c|c|c|}
\hline & \multicolumn{3}{|c|}{ Procedure } \\
\hline & Open surgery & $\begin{array}{l}\text { Percutaneous } \\
\text { endoscopic } \\
\text { lithotomy }\end{array}$ & $\begin{array}{l}\text { Second generation } \\
\text { extracorporeal } \\
\text { shockwave lithotripsy }\end{array}$ \\
\hline Size of incision $(\mathrm{cm})$ & $20-30$ & 1 & None \\
\hline Time of hospitalisation (days) & $12-14$ & 2 & None \\
\hline Time of convalescence & 12 weeks & 3 days & $\begin{array}{l}\text { Immediate return to } \\
\text { normal activities }\end{array}$ \\
\hline Operation time & $2-3$ hours & 1 hour & $30-45 \mathrm{mins}$ \\
\hline Blood replacement (units) & $2-6$ & $0-2$ & None \\
\hline Anaesthetic & General & General & None \\
\hline Analgesics & Heavy opioids & Minor non-opioids & $\begin{array}{l}\text { None or minor } \\
\text { non-opioids }\end{array}$ \\
\hline Complications & $\begin{array}{l}\text { Pulmonary emboli, pneumonia } \\
\text { fistulas, wound infections, } \\
\text { cardiac infarcts, shock, } \\
\text { incisional hernias, and } \\
\text { septicaemia }\end{array}$ & Septicaemia & $\begin{array}{l}\text { Ureteric obstruction } \\
\text { from stone fragments }\end{array}$ \\
\hline
\end{tabular}

\section{The ureteric stone}

Thirteen years ago treating patients with a stone in the ureter depended mainly on the stone's size. For a stone below $5 \mathrm{~mm}$ in diameter patients were treated expectantly with analgesics and antispasmodics in the hope that it would pass spontaneously. For larger stones surgery was the only option: open surgery required a $10-15 \mathrm{~cm}$ wound followed by six or seven days in hospital and a minimum of one month'sconvalescence. In 1980 Perez-Castro and

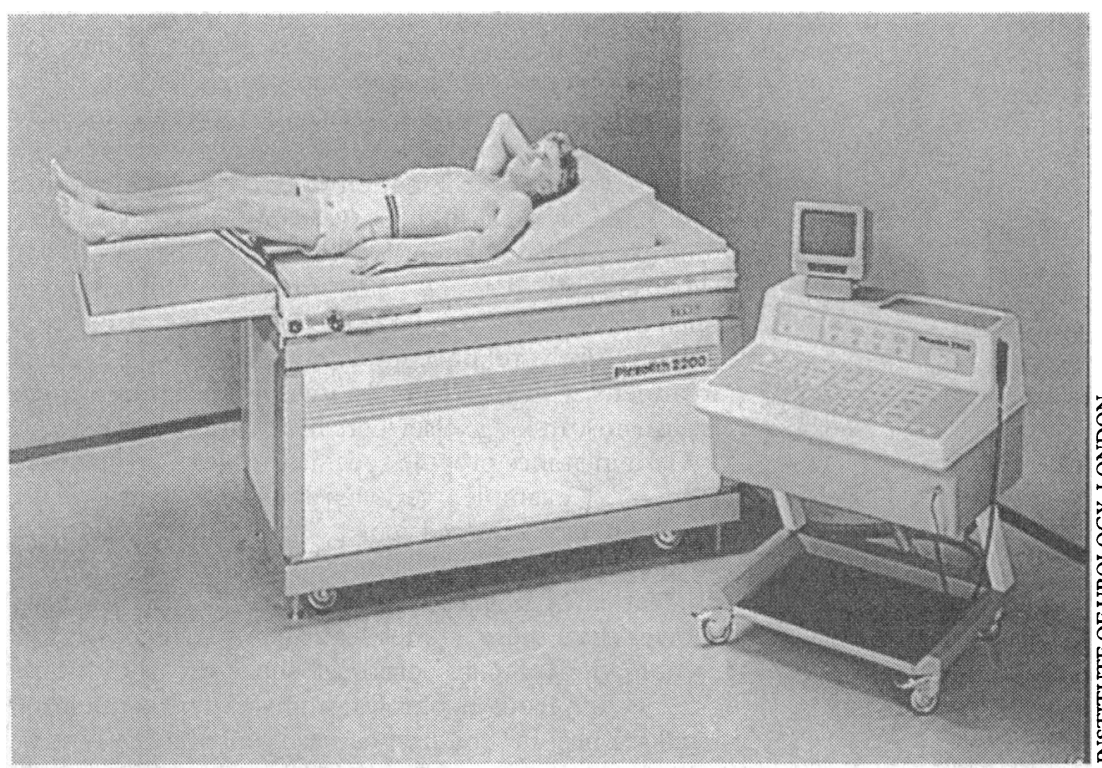

Second generation piezoelectric lithotripter
Martinez-Pinero reported the use of their fine calibre ureteroscope, which could be passed through the ureteric orifice and up the full length of the ureter to the kidney. ${ }^{35}$ Ureteric stones could be visualised with this instrument and fragmented with ultrasonic or electrohydraulic probes; the pieces could then be removed with a small ureteric stone basket. About $60-70 \%$ of stones could be treated with this device, particularly those lodged in the lower ureter. ${ }^{36}$ At 11.5 French gauge, however, the instrument was somewhat traumatic.

In 1986 the development of a pulsed dye laser with a $200 \mu \mathrm{m}$ fibre capable of fragmenting urinary calculi ${ }^{37} 38$ permitted the design of much finer ureteroscopes of about 7 French gauge, which could easily be passed up the undilated ureter. The laser fibre was advanced through the operating channel of the endoscope to a stone: this was fragmented to pieces smaller than $2 \mathrm{~mm}$ in diameter, which could be passed spontaneously. With this facility nearly $85 \%$ of ureteric stones could be accessed and treated. ${ }^{39} 40$ Stones that could not be reached by solid ascending ureteroscopy could be accessed by flexible retrograde ureteroscopy or by renal puncture, allowing a fine solid rod or flexible endoscope to be passed down to the stone from above. The stone would then be fragmented with an electrohydraulic, ultrasonic, of laser probe and removed. ${ }^{41}$ Patients whose ureteric stones are treated endoscopically show notable lack of morbidity: patients treated with the miniscope and laser can usually be dealt with as day cases, or at most in a one night stay, and can normally return to work within 48 hours. ${ }^{42}$

Various extracorporeal lithotripters have also been used to treat ureteric stones. With suitable positioning of the patient and localisation of the stone, usually with the $x$ ray imaging facility on many machines, stones in the upper and lower thirds of the ureter may be visualised and brought into focus for fragmentation. ${ }^{43-45}$ Stones in the middle third of the ureter provide the greatest problem: they are usually inaccessible to $x$ ray imaging and require ureteroscopy and lasertripsy. If this is not possible the stone may be flushed back into the kidney by insertion of a retrograde catheter to be treated by extracorporeal lithotripsy in the kidney, where it can be suitably visualised.

\section{The bladder stone}

Bladder stones were traditionally treated transurethrally and fragmented with an optical or mechanical lithotrite. For the past 20 years, however, stones had occasionally been broken by electrohydraulic discharge, and this method has recently become standard procedure, with endoscopic visualisation of the stone and then fragmentation by an electrohydraulic probe. Open surgery is now unnecessary except for massive calculi.

\section{Conclusion}

The reduced mortality and morbidity associated with these minimally invasive techniques have brought considerable benefit to patients with renal tract stones. The suggestion that these methods result in higher rates of recurrence of stones than those achieved by open surgery is clearly incorrect ${ }^{24} 46$ : the $7 \%$ rate of recurrence for renal oxalate stones at three years after treatment is slightly better than rates reported after open surgery. ${ }^{47}$ In addition, several groups have reported the considerable economic savings produced by endourological methods and extracorporeal lithotripsy. ${ }^{147}$

The whole of the renal collecting system where stones may form or lodge is now readily accessible to 


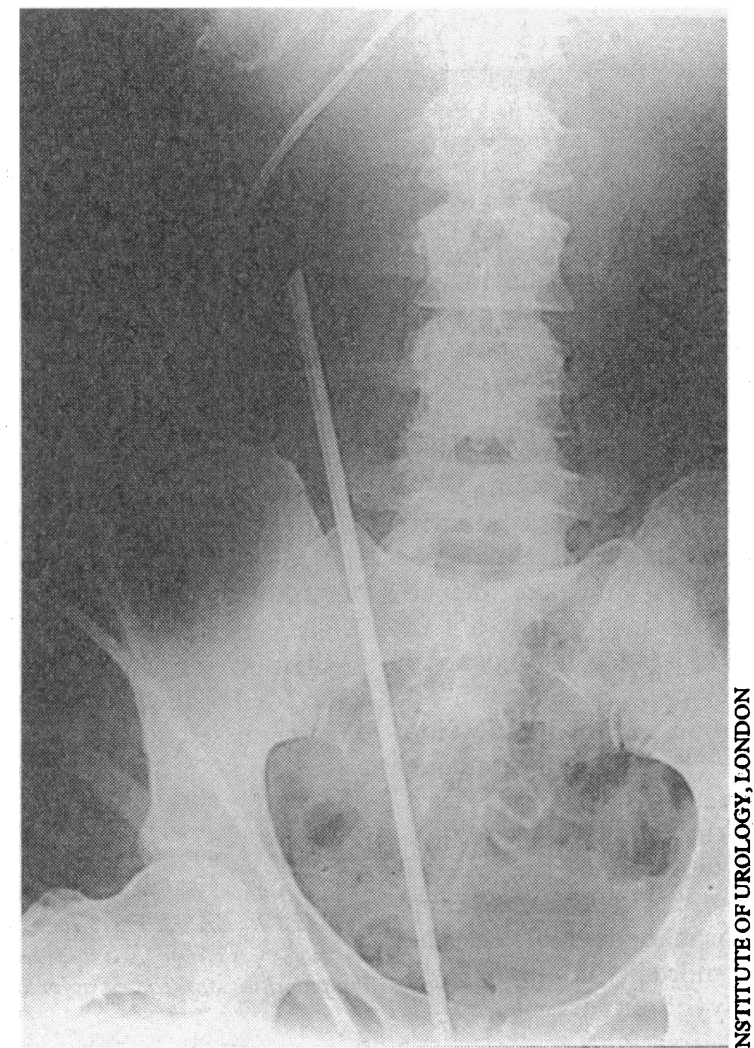

Solid ureteroscope inserted in ureter

these methods and almost all urinary stones can be removed without resorting to open surgery. Unfortunately, the facilities for these techniques are still by no means universally available in the United Kingdom, and much open surgery is still apparently being carried out with little public or professional demand that this should cease.

1 Charig CR, Webb DR, Payne SR, Wickham JEA. Comparison of treatment of renal calculi by open surgery, percutaneous nephrolithotomy, and extracorporeal shockwave lithotripsy. BMF 1986;292:879-82.

2 Alken P, Hutschenreiter G, Gunther R. Percutaneous kidney stone removal. Eur Urol 1982;8:304-11.

3 Wickham JEA, Kellett MJ. Percutaneous nephrolithotomy. BMF1981;283: 1571.

4 Alken $P$, Gunther $R$, Thuroff J. Percutaneous nephrolithotomy a routine procedure? Br F Urol 1983;suppi:1-5.

5 Marberger $M$. Ultrasonic lithotripsy of renal calculi and 3 year experience. BrF Urol 1983;suppl:41-50.

6 Smith AD, Lee WJ. Percutaneous stone extraction. Br f Urol 1983;suppl: 84-5.

7 Clayman RV, Miller RP, Surya WR, Casteneda-Zuniga WR, Smith AD Amplatz $\mathrm{K}$, et al. Nephrostolithotomy: percutaneous removal of renal and ureteric calculi. Br f Urol 1983;suppl:6-10.

8 Segura JW, Patterson DE, Leroy AJ, May GR, Smith LH. Percutaneous lithotripsy. F Urol 1983;130:1051-4.

9 Wickham JEA, Kellett MJ, Miller RA. Elective percutaneous nephrolithotomy in 50 patients; an analysis of the technique results and complications. FUrol 1983;129:904-6.

10 Wickham JEA, Miller RA, Kellett MJ. Percutaneous nephrolithotomy: results and cost effectiveness. Br G Urol 1983;suppl:103-6.

11 Clayman RV, Surya V, Hunter D, Castenada-Zuniga WR, Miller RP, Coleman C, et al. Renal vascular complications associated with the percutaneous removal of renal calculi. $\{$ Urol 1984;132:228.

12 Chaussy C, Brendel W, Schmedt E. Extracorporeally induced destruction of kidney stones by shockwaves. Lancet 1980;ii:1265-8.

13 Marberger M, Turk C, Steinkogler I. Painless piezoelectric extracorporea lithotripsy. $\mathcal{F}$ Urol 1988;139:695-9.

14 Philp T, Whitfield HN, Kellett MJ, Wickham JEA. Painless lithotripsy. Experience with 100 patients. Lancet 1988;i:41.

15 Vallencien G, Auiles G, Munoz R, Veillon B, Charton M, Brisset M Piezoelectric extracorporeal lithotripsy by ultrashort waves with EDAP LTO1 device. $f$ Urol 1988;139:689.

16 Lingeman JE, Kulb TB. Hypertension following extracorporeal shockwave lithouripsy. $f$ Urol 1987;137:142 abstract 154.
17 Williams CM, Kaude JV, Newman RC. Extracorporeal shockwave lithotripsy. American fountla of Radiology 1988;150:311-5.

18 Lingeman JE, Woods JR, Toth PD. Blood pressure changes following extracorporeal shockwave lithotripsy and other forms of nephrolithiasis. JAMA 1990;263:1789-94

19 Damm O, Tiselius HG. Some observations on the effects on ESWL treatment. Scandinavian foumal of Urology 1986;20(suppl 101):29.

20 Marcellan FJR, Servio LI. Evaluation of renal damage in extracorporeal lithotripsy by shockwaves. Eur Urol 1986;12:73-5.

21 Haupt G, Haupt A, Donovan JM, Drach GW, Chaussy C. Short term changes of laboratory values after extracorporeal shockwave lithotripsy - a comparative study. F Urol 1989;142:250-62.

22 Wickham JEA, Mathur VK. Hypothermia in the conservative surgery of renal disease. Br f Urol 1971;43:648-57.

23 Fuchs GJ, Chaussy CG. ESWL for staghorn disease. Reassessment of our treatment strategy. World fourmal of Urology 1987;5:237-44.

24 Segura JW, Patterson DE, Leroy AJ, Williams HJ Jr, Bassett DM, Benson RC Jr, et al. Percutaneous removal of kidney stones: Review of 1000 cases. IUnol 1985;134:1077-80.

25 Rassweiler J, Gumpinger R, Eisenberger F. Multimodal treatment (extracorporeal shockwave lithotripsy and endourology) of complicated renal stone disease. Eur Urol 1986;12:294-304.

26 Schulze H, Hertle L, Graff J, Funke PJ, Senge T. Combined treatment of branched calculi by percutaneous nephrolithotomy and extracorporeal shockwave lithotripsy. F Urol 1986;135:1138-41.

27 Gleeson MJ, Griffith DP. Extracorporeal shockwave monotherapy for larger renal calculi. Br f Urol 1989;142:259-62.

28 Fuchs GJ, Stenzl A, Zimmern P, Royce PL. Results of non-surgical uric acid and cystine calculi treatment. In: Walker R, Sutton RAL, Cameron ECB, Pak YC, Robertson WG, eds. Urolithiasis. London: Plenum Press, 1988: 963-5.

99 Psihramis KE; Dretler S. Extracorporeal shockwave lithotripsy of calyceal diverticular calculi. $₹$ Urol 1987;138:707-11.

30 Jones DJ, Wickham JEA, Kellett MJ. Percutaneous nephrolithotomy for calculi in horseshoe kidneys. $¥$ Urol 1991;145:481-3.

1 Baskin L, Floth A, Stoller ML. The horseshoe kidney therapeutic considerations with urolithiasis. Fournal of Endourology 1989;3:51-8.

32 Holmes SAV, Eardley I, Corry DA, Nockler I, Whitfield HN. The use of extracorporeal shockwave lithotripsy for medullary sponge kidneys. Br f Urol 1992;72:352-4.

33 Newman PM, Coury T, Lingeman JE, Mertz JHO, Mosbaugh PG, Steele RE, et al. Extracorporeal shockwave lithotripsy-experience in children. F Urol 1986;136:238-40.

34 Turk CH, Steinkogler I, Marberger M. ESWL in children. AKT Urology 1990;21(suppl):89-92.

35 Perez-Castro E, Martinez-Pinero JA. La ureter renoscopia transureteral. Ach Esp Urol 1980;33:445.

36 Coptcoat MJ, Webb DR, Kellett MJ, Whitfield HN, Wickham JEA. The treatment of 100 consecutive patients with ureteral calculi in a British Stone Centre. IUrol 1987;137:1122.

37 Watson GM, Wickham JEA. Initial experience with a pulsed dye laser for ureteric calculi. Lancet 1986;: 1357-8.

38 Dretler SP. Laser photofragmentation of ureteral calculi. Endourology Newsletter 1986;1(4):13.

39 Coptcoat MJ, Ison KT, Watson G, Wickham JEA. Lasertripsy for uretera stones; 100 clinical cases. Foumal of Endourology 1987;1:119.

40 Stackle N, Marberger M. Late sequelae of the management of ureteric calculi with the uretero-renoscope. F. Unol 1986;136:386.

41 Begun FP, Lawson RK, Remynse LC, Jacobs SC. Flexible ureterorenoscopy: report of 97 consecutive procedures. Foumal of Endourology 1992;6:347.

42 Dretler SP. An evaluation of ureteral laser lithotripsy, 225 consecutive patients. $f$ Urol 1990;143:267-71.

43 Tiselius H, Petterson B, Andersson A. Extracorporeal shockwave lithotripsy of stones in the mid-ureter. $\mathcal{\text { Urol }}$ 1989;141:280.

44 Rassweiler J, Schmidt A, Gumpinger R, Mayer R, Eisenberger F. ESWL for ureteric calculi using the Dornier HM3, HM3 and Wolf Piezolith. $f$ Urol 1990;96:149-53.

45 Becht E, Moll V, Neisius D, Zeigler M. Treatment of pre-vesical ureteric calculi by extracorporeal shockwave lithotripsy. $f$ Urol 1988;139:916.

46 Liedl B, Jocham D, Schuster C, Lunz C. Long term results in ESWL treated stone patients. In: Walker VR, Sutton AL, Cameron ECB, Pak CYC Robertson WG. Urolithiasis. London: Plenum Press, 1989:929.

47 Vahlensieck W. Epidemiologie, Allgemeine kausal und formalgenase diagnostick. In: Valensiecle W, ed. Urolithiasis. Berlin: Springer-Verlag, 1979:110-2.

\section{Correction}

\section{ABC of Emergency Radiology: Chest radiographs-1}

Several errors occurred in this article by $\mathrm{D} W$ Hodgkinson and colleagues (6 November, pp 1202-6). In figure 1 two of the label are wrong. Number 3 should be left pulmonary artery and number 4 left hilum. The second sentence in the legend to figure 4 should state that cardiac shadow seems to move to the left and not the right. On p 1204 the last sentence of the last paragraph should refer to the heart's full diameter and not the diaphragm's full diameter. 